\title{
Prenošenje toplote u gravitacionoj toplotnoj cevi
}

U sled promene faze fluida, toplotna cev ima veoma visoku efektivnu toplotnu provodljivost i može da prenosi velike toplotne protoke i pri malim razlikama temperatura. U radu su date fizičke osnove funkcionisanja i prikazan je model prenošenja toplote u gravitacionoj toplotnoj cevi - termosifonu. Analiza dobijenih rezultata je izvršena za različite dimenzije toplotnih cevi, različite kombinacije radnog fluida i materijala cevi, kao i različite uslove rada. Dobijeni rezultati daju osnova za širu primenu toplotnih cevi u procesnoj tehnici.

\section{Uvod}

U svom najjednostavnijem obliku, gravitaciona toplotna cev - termosifon predstavlja šuplju metalnu cev napunjenu određenom količinom radnog fluida. U principu, termosifon je moguće podeliti na tri oblasti: isparivačku, adijabatsku (koja može ali i ne mora postojati) i kondenzacijsku oblast (slika 1). Usled prijema toplote radni fluid $u$ isparivačkom delu isparava, zatim para struji ka kondenzacijskom delu cevi, gde se usled predaje toplote kondenzuje. Kretanje kondenzata ka isparivačkoj oblasti se obezbeđuje ili kapilarnim silama (fitiljastom strukturom unutar cevi) ili, u slučaju termosifona, gravitacionom silom. Tako se unutar cevi/termosifona formira zatvoreni tok fluida koji menja fazu, pa se toplota iz jedne u drugu oblast prenosi značajno bolje nego u slučaju šipke punog poprečnog preseka od istog materijala. Radi strujanja fluida u termosifonu, isparivački deo mora da bude ispod kondenzacijskog dela.

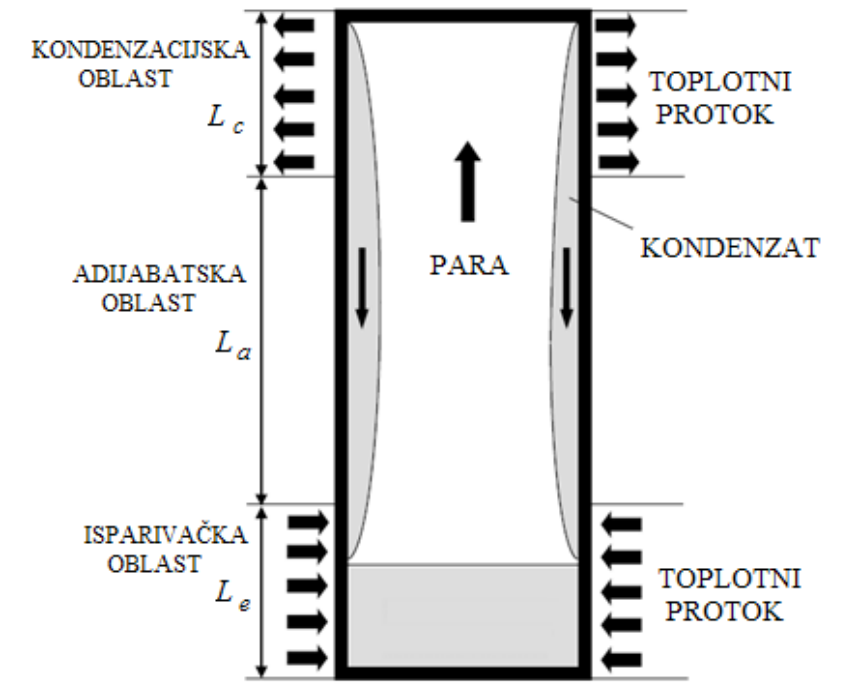

Slika 1: Šematski prikaz termosifona
Određena toplotna cev (termosifon) je predviđena za rad u odgovarajućem temperaturnom opsegu, pa se shodno tome bira i odgovarajući radni fluid. Takođe, mora se obratiti pažnja na hemijsku kompatibilnost fluida sa materijalom cevi, kako zbog mogućeg stvaranja nekondenzujućih gasova (koji negativno utiču na funkcionisanje termosifona), tako i zbog moguće pojave korozije. Pri izboru materijala cevi, osim na toplotnu provodljivost i kompatibilnost sa fluidom, mora se obratiti pažnja i na čvrstoću, poroznost, i dr.

\section{$2 \quad$ Model prenošenja toplote}

Bilo koji način prenošenja toplote uslovljen je razlikom temperatura, i što je ona veća veći je i toplotni protok. Međutim, u mnogim slučajevima, poželjno je prenošenje većih toplotnih protoka ali pri relativno malim razlikama temperatura. U termosifonu para (pri temperaturi zasićenja) nosi velike vrednosti latentne toplote iz isparivačke u kondenzacijsku oblast. Tako je jedna od najjednostavnijih prednosti termosifona prenošenje velikih protoka toplote skoro pri izotermskim uslovima promene faze, što dvofazni termosifon čini idealnim izborom za primene u slučaju malih temparaturnih gradijenata.
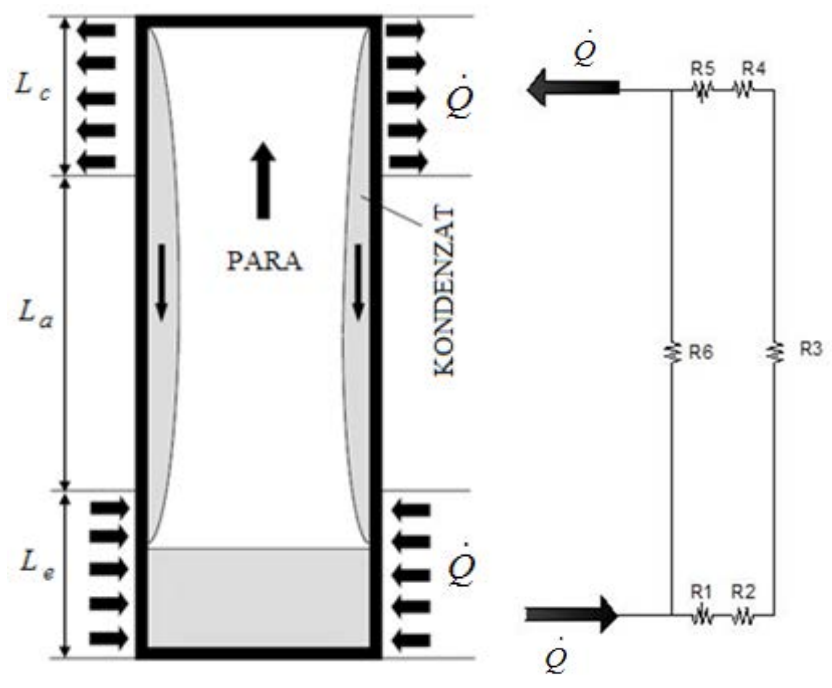

Slika 2: Šema toplotnih otpora

Prenošenje toplote $\mathrm{u}$ termosifonu zavisi od različitih faktora, uključujući osobine radnog fluida, geometriju i položaj termosifona, temperaturnu oblast rada, pritisak i dr. Prenošenje toplote u ovom slučaju obuhvata složene procese promene faza, kretanja fluida, suprotnosmernog strujanja faza, provođenja. Ovde je prikazana analiza prenošenja toplote pri ustaljenim uslovima. Model prenošenja 
toplote prikazan u ovom radu se oslanja na analogiju sa prenosom električne energije. Toplotni protok, $\dot{Q}$ između bilo koje dve sredine moguće je izraziti kao

$$
\dot{Q}=\frac{\Delta t}{R}
$$

gde je $\Delta t$ razlika temperatura između dve sredine a R odgovarajući otpor prenošenju toplote. Prenošenje toplote u termosifonu je predstavljeno preko mreže toplotnih otpora, redno i paralelno povezanih. $\mathrm{Na}$ slici 2 je prikazana šema otpora prenosu toplote u termosifonu. Sa $\mathrm{R}_{1} \mathrm{i} \mathrm{R}_{5}$ su označeni otpori provođenju toplote kroz zid cevi u radijalnom pravcu $\mathrm{u}$ isparivačkom $\mathrm{i}$ kondenzacijskom delu.

Otpori su definisani poznatim izrazima

$$
R_{1}=\frac{1}{2 \pi L_{\mathrm{e}} \lambda_{\mathrm{w}}} \ln \frac{r_{s}}{r_{u}} \quad \mathrm{i} \quad R_{5}=\frac{1}{2 \pi L_{c} \lambda_{\mathrm{z}}} \ln \frac{r_{s}}{r_{u}}
$$

gde su: $\lambda_{w}$ - toplotna provodljivost materijala cevi, $\mathrm{L}_{\mathrm{e}} \mathrm{i} \mathrm{L}_{\mathrm{c}}$ - dužina isparivačkog i kondenzacijskog dela, $r_{u}$ i $r_{s}$ - unutrašnji i spoljašnji poluprečnik termosifona u odgovarajućoj oblasti.

$\mathrm{Sa}_{2} \mathrm{i} \mathrm{R}_{4}$ su označeni otpori prelaženju toplote pri isparavanju i pri kondenzaciji fluida. Otpori su definisani izrazima

$$
R_{2}=\frac{1}{2 \pi r_{u} L_{\mathrm{e}} \alpha_{e}} \quad \text { i } \quad R_{4}=\frac{1}{2 \pi r_{u} L_{\mathrm{c}} \alpha_{c}}
$$

gde su: $\alpha_{\mathrm{e}}$ - srednja vrednost koeficijenta prelaženja toplote pri isparavanju, $\alpha_{c}$ - srednja vrednost koeficijenta prelaženja toplote pri kondenzaciji.

Koeficijenti prelaženja toplote pri isparavanju i kondenzaciji su određivani iz izraza dobijenog primenom Nuseltove teorije filmske kondenzacije za vertikalnu površ, tj:

$$
\alpha=0,943 \sqrt[4]{\frac{\lambda_{l}^{3} g \cos \theta\left(\rho_{l}-\rho_{v}\right)^{2} r}{\mu_{l} L\left(t_{\text {sat }}-t_{w}\right)}}
$$

gde je: $\lambda_{1}$ - toplotna provodljivost tečnosti, $\mu_{1}$ - dinamička viskoznost tečnosti, $r$ - toplota isparavanja (kondenzacije) fluida, $\theta$ - ugao nagiba termosifona, $\rho_{1}$ i $\rho_{v}$ - gustina tečne i parne faze, $t_{\text {sat }}$ - temperatura zasićenja, $\mathrm{t}_{\mathrm{w}}$ - temperatura unutrašnje površi termosifona $u$ datoj oblasti, L - dužina odgovarajuće oblasti (isparivačke ili kondenzacijske) termosifona. Iz razloga što je debljina filma kondenzata na zidu mnogo manja od prečnika cevi, razmatran je proces kondenzacije na ravnoj površi, pre čemu je ovde razmatran samo vertikalni položaj.

$\mathrm{Sa}_{3}$ je označen otpor povezan sa padom temperature pare $\mathrm{u}$ aksijalnom pravcu termosifona. Izraz za $R_{3}$ je [4]:

$$
R_{3}=\frac{8 L_{\mathrm{o}} R \mu_{\mathrm{v}}\left(\frac{t_{\text {sat }, e}-t_{\text {sat }, c}}{2}\right)^{2}}{\pi r^{2} p_{\mathrm{v}} \rho_{\mathrm{v}} r_{u}^{4}}
$$

gde je: $t_{\text {sat,e }}$ - temperatura zasićenja $u$ isparivaču, $t_{\text {sat,c }}$ - temperatura zasićenja pare $\mathrm{u}$ kondenzatoru, $\mathrm{p}_{\mathrm{v}}, \rho_{\mathrm{v}}, \mu_{\mathrm{v}}, \mathrm{R}$ - pritisak, gustina, dinamička viskoznost i gasna konstanta pare, $r$ - toplota isparavanja i
$\mathrm{L}_{\mathrm{o}}$ - ukupna dužina termosifona.

Otpor provođenju toplote kroz zid termosifona u aksijalnom pravcu, $\mathrm{R}_{6}$, je dat izrazom

$$
R_{6}=\frac{0,5\left(L_{\mathrm{e}}+L_{\mathrm{c}}\right)+L_{\mathrm{a}}}{\lambda_{w} \pi\left(r_{s}^{2}-r_{u}^{2}\right)}
$$

Toplotni protok koji prenosi termosifon iz isparivačke u kondenzacijsku oblast iznosi:

$$
\dot{Q}=\frac{t_{\mathrm{w}, \mathrm{e}, \mathrm{e}}-t_{\mathrm{w}, \mathrm{s}, \mathrm{c}}}{R_{\mathrm{e}}}
$$

gde je: $t_{w, s, e}$ - temperatura spoljašnje površi termosifona $u$ isparivačkoj oblasti, $t_{\mathrm{w}, \mathrm{s}, \mathrm{c}}$ - temperatura spoljašnje površi termosifona $\mathrm{u}$ kondenzacijskoj oblasti i $\mathrm{R}_{\mathrm{e}}$ - ekvivalentni toplotni otpor termosifona. S obzirom da je ukupni otpor kombinacija redno i paralelno vezanih otpora, važi

$$
R_{\mathrm{e}}=\frac{R_{\mathrm{e}}^{\mathrm{r}} R_{6}}{R_{\mathrm{e}}^{\mathrm{r}}+R_{6}}
$$

Sa Rer je označen ekvivalentni toplotni otpor redno vezanih otpora, dat izrazom

$$
R_{\mathrm{e}}^{\mathrm{r}}=R_{1}+R_{2}+R_{3}+R_{4}+R_{5}
$$

\section{Procedura proračuna}

Proračun je izvršen iterativnim postupkom. Proračun počinje pretpostavljanjem temperatura $t_{w, s, e}, t_{w, u, e}, t_{s a t, e}, t_{s a t, c}, t_{w, u, c}, t_{w, s, c}, p a$ se onda, za izabrani radni fluid, vrši određivanje njegovih merodavnih termofizičkih veličina, a zatim, prema navedenim izrazima, određivanje vrednosti toplotnih otpora i toplotnog protoka. Na osnovu izračunatih toplotnih otpora i toplotnog protoka vrši se izračunavanje pretpostavljenih temperatura primenom izraza:

$$
\begin{aligned}
& t_{w, s, e}=t_{w, s, c}+\dot{Q} R_{e} \\
& t_{\mathrm{w}, \mathrm{u}, \mathrm{e}}=t_{\mathrm{w}, \mathrm{s}, \mathrm{e}}-\left(\dot{Q}-\frac{\left(t_{\mathrm{w}, \mathrm{s}, \mathrm{e}}-t_{\mathrm{w}, \mathrm{s}, \mathrm{c}}\right)}{R_{6}}\right) R_{1} \\
& t_{\mathrm{sat}, \mathrm{e}}=t_{\mathrm{w}, \mathrm{u}, \mathrm{e}}-\left(\dot{Q}-\frac{\left(t_{\mathrm{w}, \mathrm{s}, \mathrm{e}}-t_{\mathrm{w}, \mathrm{s}, \mathrm{c}}\right)}{R_{6}}\right) R_{2} \\
& t_{\mathrm{sat}, \mathrm{c}}=t_{\mathrm{sat}, \mathrm{e}}-\left(\dot{Q}-\frac{\left(t_{\mathrm{w}, \mathrm{s}, \mathrm{e}}-t_{\mathrm{w}, \mathrm{s}, \mathrm{c}}\right)}{R_{6}}\right) R_{3} \\
& t_{\mathrm{w}, \mathrm{u}, \mathrm{c}}=t_{\mathrm{sat}, \mathrm{c}}-\left(\dot{Q}-\frac{\left(t_{\mathrm{w}, \mathrm{s}, \mathrm{e}}-t_{\mathrm{w}, \mathrm{s}, \mathrm{c}}\right)}{R_{6}}\right) R_{4}
\end{aligned}
$$

Sa izračunatim temperaturama proračun se nastavlja u sledećoj iteraciji, i ponavlja iz iteracije u iteraciju, sve dok se vrednosti svih temperatura iz poslednje i pretposlednje iteracije, u granicama zadane tačnosti, ne poklope. Proračun vršen primenom razvijenog računarskog programa. Program pruža mogućnosti analize različitih uticajnih veličina na prenošenje toplote u termosifonu, npr. geometrije, nagiba i materijala cevi, izbor različitih fluida i dr. 


\section{PT Inženjerska praksa}

\section{$4 \quad$ Rezultati i analiza}

Rezultati koji dobijeni proračunom proračunom prikazani su na slikama od br. 3 do br. 7. Izvršena je analiza uticaja različitih dimenzija i materijala cevi kao i različitih radnih fluida na radne karakteristike termosifona. Materijal cevi i radni fluid su birani tako da budu kompatibilni. Proračun je prikazan za sledeće kombinacije materijala cevi i radnog fluida: bakar - voda, aluminijum - amonijak, aluminijum - freon 11, nerđajući čelik - ugljen dioksid. Za usvojene temperature spoljašnje površi termosifona u kondenzacijskoj oblasti, na dijagramima je prikazana zavisnost toplotnog protoka od temperature spoljašnje površi termosifona u isparivačkoj oblasti. Pri izboru materijala cevi i radnih temperatura vođeno je računa i o pritisku fluida koji se javlja unutar termosifona, koji je naročito visok u slučaju ugljendioksida kao radnog fluida. U ovom radu je prikazano kako promene dimenzija, poluprečnika i dužine, utiču na prenošenje toplote u termosifonu. Analiza je izvršena za spoljašnje poluprečnike od $50 \mathrm{~mm}, 25 \mathrm{~mm}$ i 5 $\mathrm{mm}$, dok su analizirane dužine termosifona iznosile $2 \mathrm{~m}, 1 \mathrm{~m} \mathrm{i} 0,5 \mathrm{~m}$. U svim analiziranim slučajevima uzimano je da dužina isparivačkog, kondenzacijskog i adijabatskog dela iznose 70\%, 20\% i 10\% od ukupne dužine termosifona, tj. $\mathrm{L}_{\mathrm{e}}=0,7 \mathrm{~L}_{\mathrm{o}} ; \mathrm{L}_{\mathrm{c}}=0,2 \mathrm{~L}_{\mathrm{o}} ; \mathrm{L}_{\mathrm{a}}=0,1 \mathrm{~L}_{\mathrm{o}}$.

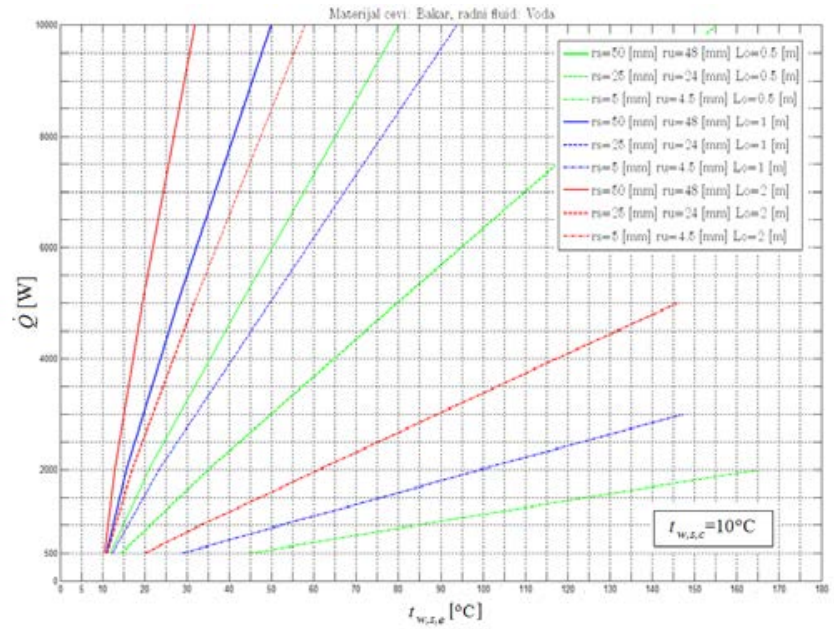

(a)

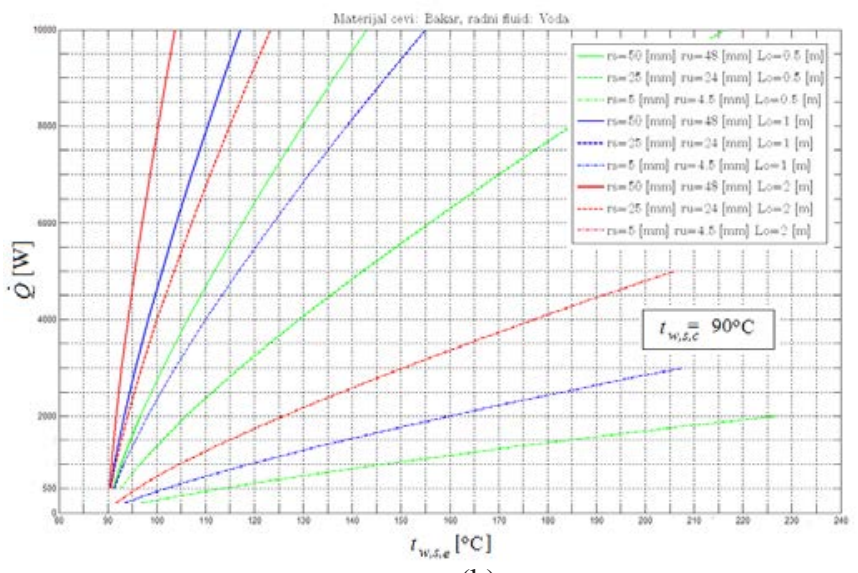

(b)

Slika 3: Termosifon bakar-voda: zavisnost toplotnog protoka od temperature $\mathrm{u}$ isparivačkom delu i od dimenzija termosifona:

a) $\left.\mathrm{t}_{\mathrm{w}, \mathrm{s}, \mathrm{c}}=10^{\circ} \mathrm{C}, \mathrm{b}\right) \mathrm{t}_{\mathrm{w}, \mathrm{s}, \mathrm{c}}=90^{\circ} \mathrm{C}$.

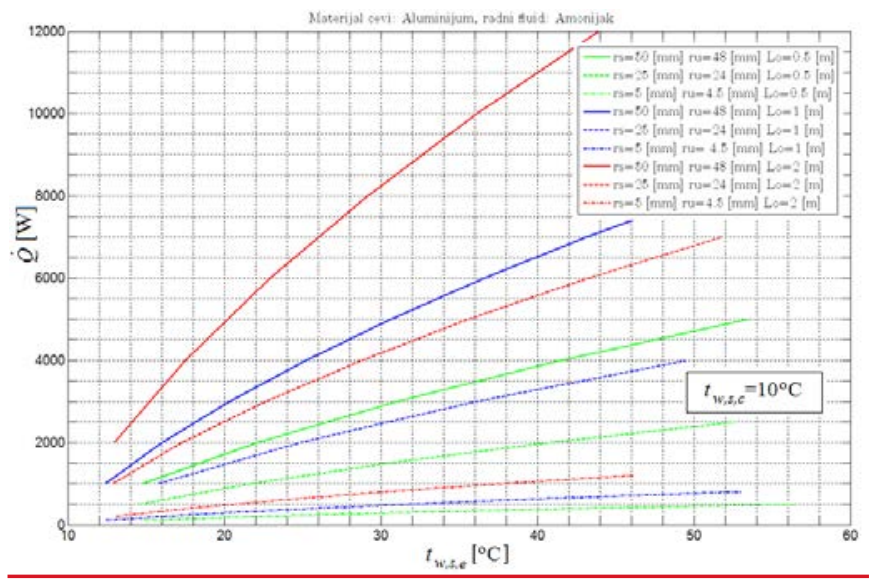

Slika 4: Termosifon aluminijum-amonijak: zavisnost toplotnog protoka od temperature $\mathrm{u}$ isparivačkom delu i od dimenzija termosifona

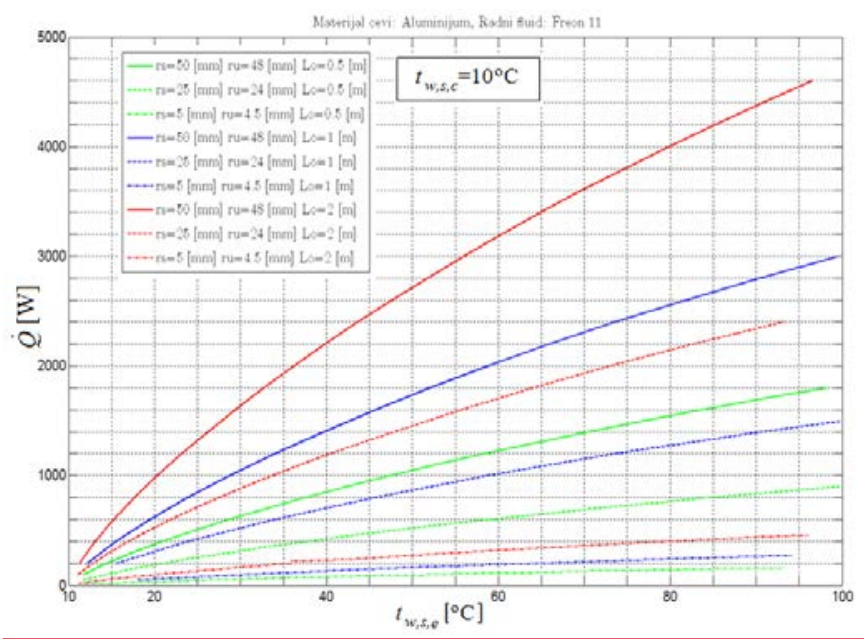

Slika 5: Termosifon aluminijum-freon 11: zavisnost toplotnog protoka od temperature $\mathrm{u}$ isparivačkom delu i od dimenzija termosifona

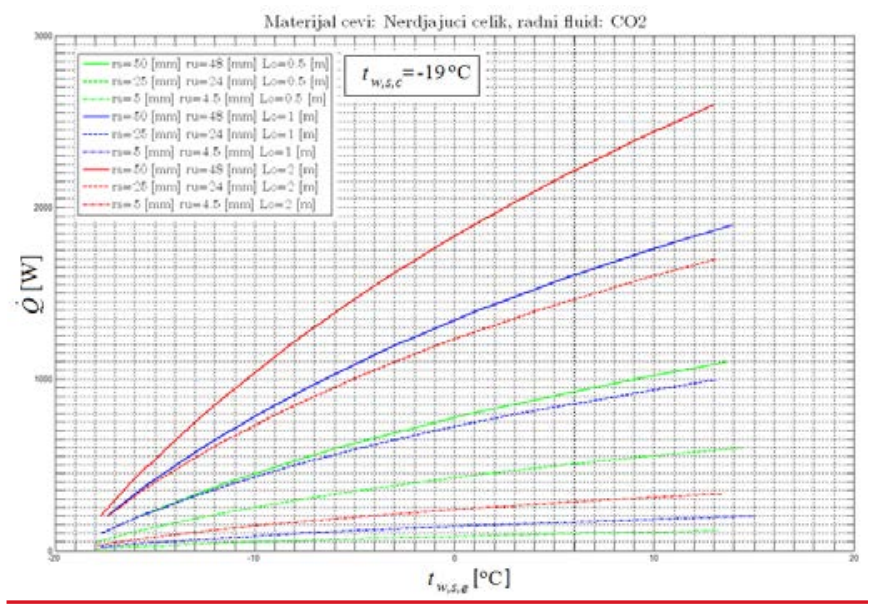

Slika 6: Termosifon čelik-ugljendioksid: zavisnost toplotnog protoka od temperature $\mathrm{u}$ isparivačkom delu i od dimenzija termosifona.

Za kombinaciju bakar-voda na slici br. 3 prikazana je zavisnost toplotnog protoka od temperatura $u$ isparivačkom delu i dimenzija termosifona. Za termosifon aluminijum-amonijak zavisnost je prika- 
zana na slici br 4, za termosifon aluminijum-freon 11 na slici br. 5 i za termosifon čelik-ugljendioksid na slici br. 6. Dijagrami su prikazani za poznatu temperaturu u kondenzacijskoj oblasti naznačenu na dijagramima.

Iz dijagrama moguće je zapaziti da pri istoj razlici temperatura, povećanjem poluprečnika cevi dolazi do povećanja toplotnog protoka u približno istom odnosu, dok povećanjem dužine termosifona dolazi do povećanja toplotnog protoka ali u manjem odnosu. Takođe, mogu se zapaziti i razlike u vrednostima toplotnih protoka za različite kombinacije materijala cevi i radnog fluida.

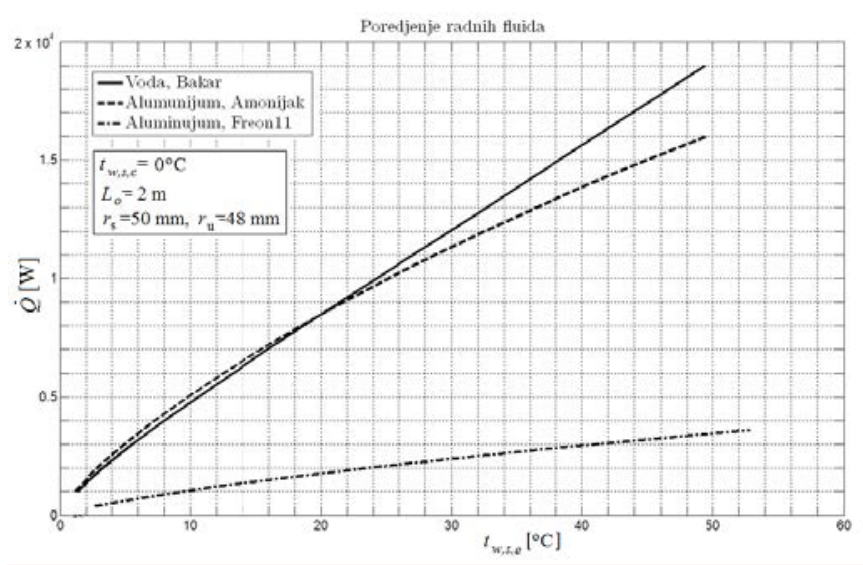

Slika 7: Poređenje termosifona sa različitim radnim fluidima

Na slici br. 7 prikazano je poređenje tri kombinacije materijala cevi i radnog fluida: bakar-voda, aluminijum-amonijak i aluminijumfreon 11 za dužinu termosifona od $2 \mathrm{~m}$, spoljašnji poluprečnik od 50 $\mathrm{mm}$ i za temperaturu kondenzatora od $0{ }^{\circ} \mathrm{C}$. Sa dijagrama se može uočiti da termosifon sa amonijakom prenosi najveću količinu toplote do nekih $20^{\circ} \mathrm{C}$ temperature isparivača. Iznad temperature od $20{ }^{\circ} \mathrm{C}$ kriva za amonijak sporije raste od krive vode, što znači da iznad te temperature voda bolje prenosi toplotu. U datoj oblasti temperatura, freon 11 prenosi neuporedivo manje toplotne protoke od vode $\mathrm{i}$ amonijaka. Za slučaj vode kao radnog fluida moguće je zapaziti da pri istoj razlici temperatura termosifon prenosi veći toplotni protok ako radi u oblasti viših temperatura (slika 1, b) nego u slučaju rada u oblasti nižih temperatura (slika 1, a). Pri istoj razlici temparatura termosifon bakar-voda prenosi toplotu i do 150 puta bolje od pune bakarne cevi istih dimenzija [7].

\section{$5 \quad$ Zaključak}

$\mathrm{U}$ radu je prikazan model prenošenja toplote u gravitacionoj toplotnoj cevi - termosifonu. Razvijeni model je dao očekivane rezultate, u saglasnosti sa podacima iz literature. Model daje mugućnosti analize različitih uticaja na termičke karakteristike toplotne cevi. $\mathrm{Na}$ osnovu dobijenih rezultata moguće je zaključiti da termosifon veoma efikasno, sa malim otporom, prenosi toplotu i ima široke mogućnosti primene u procesnoj tehnici i termičkom inženjerstvu.

\section{Literatura}

[1] D. Reay, P. Kew: Heat Pipes Theory, Design and Applications, Butterworth-Heinemann 2006.

[2] J. M. Ochterbeck: Heat Pipes, Department of Mechanical Engineering, Clemson University, South Carolina.

[3] H. Ma: Heat Pipes, Department of Mechanical and Aerospace Engineering, University of Missouri, Columbia.

[4] N. Miljkovic: Hybrid Solar Thermoelectric Systems Utilizing Thermosyphons for Bottoming Cycles, MSc Degree in Mechanical Engineering at MIT 2011.

[5] F. Bosnjakovic: Nauka o toplini dio prvi, Zagreb 1947.

[6] Đ. Kozic, B. Vasiljevic, V. Bekavac: Prirucnik za termodinamiku, Masinski Fakultet Beograd, 2006.

[7] N. Filipović: Termodinamička analiza rada gravitacione toplotne cevi, MSc rad, Mašinski fakultet, Beograd 2013.

\section{Autori \\ Nemanja FILIPOVIĆ \\ Auto-moto savez Srbije, Beograd}

Milan GOJAK

Univerzitet u Beogradu, Mašinski fakultet

Kraljice Marije 16, Beograd

nemanjafilipovic85@gmail.com
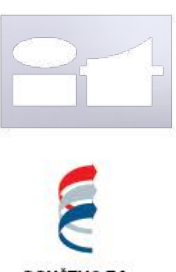

DRUŠTVOZA DRUŠTVOZA
PROCESNUTEHNIKU
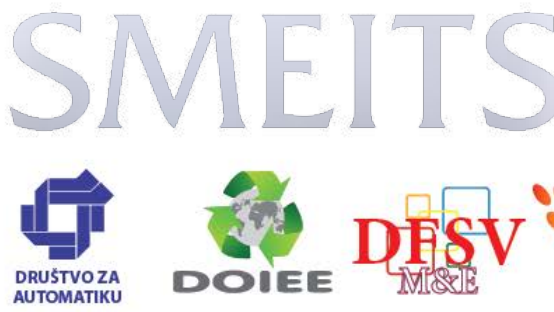
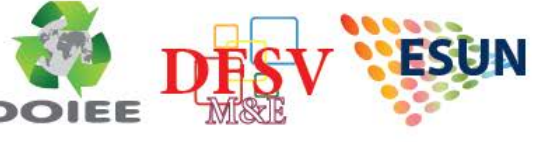

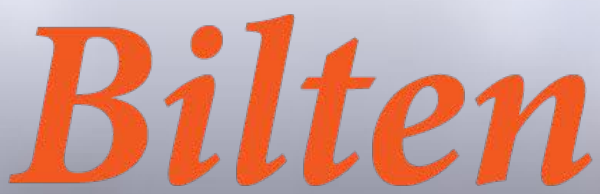

